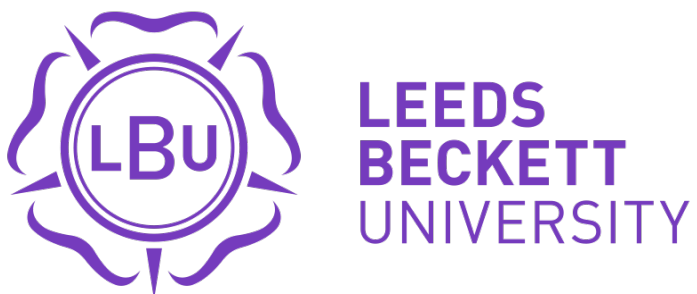

Citation:

Morgan, J (2017) Piketty and the Growth Dilemma Revisited in the Context of Ecological Economics. Ecological Economics, 136. pp. 169-177. ISSN 0921-8009 DOI: https://doi.org/10.1016/j.ecolecon.2017.02.024

Link to Leeds Beckett Repository record:

https://eprints.leedsbeckett.ac.uk/id/eprint/3585/

Document Version:

Article (Accepted Version)

Creative Commons: Attribution-Noncommercial-No Derivative Works 4.0

The aim of the Leeds Beckett Repository is to provide open access to our research, as required by funder policies and permitted by publishers and copyright law.

The Leeds Beckett repository holds a wide range of publications, each of which has been checked for copyright and the relevant embargo period has been applied by the Research Services team.

We operate on a standard take-down policy. If you are the author or publisher of an output and you would like it removed from the repository, please contact us and we will investigate on a case-by-case basis.

Each thesis in the repository has been cleared where necessary by the author for third party copyright. If you would like a thesis to be removed from the repository or believe there is an issue with copyright, please contact us on openaccess@leedsbeckett.ac.uk and we will investigate on a case-by-case basis. 


\section{Piketty and the growth dilemma revisited in the context of ecological economics}

Jamie Morgan

Leeds Beckett University

\section{Introduction}

Piketty's Capital in the Twenty-First Century (2014) has provoked considerable debate regarding the existence, sources, and significance of trends in wealth and income inequality (see Morgan, 2015a; Fullbrook and Morgan, 2014; Pressman, 2016). That debate has extended to Ecological Economics. Martins (2015) has considered the constructive potentials of aligning Piketty's work with Sen's capabilities approach within a classical political economy framework (see also Pelenc and Ballet, 2015). Jackson and Victor (2016) have addressed the challenge of no/low and degrowth posed by Piketty. Jackson and Victor's paper appears in a special section on macroeconomics in which Fontana and Sawyer (2016) provide a post-Keynesian response to the broader issue of compatibility between the ecological critique of growth and the intrinsic focus of Keynesian approaches to demand-led full employment (a response to issues raised in Holt et al., 2009). In this short paper we revisit some of the issues posed by Piketty with more of an emphasis on underlying methodological and ideological concerns. We do so using Jackson and Victor's paper as a point of departure to illustrate some basic limitations in Piketty's work and the kind of response made by Jackson and Victor from an ecological perspective.

Piketty focuses on capitalism as accumulation, explores wealth empirically, and then expresses accumulation through his three laws. However, capitalism is also a set of institutions and technologies through which accumulation is achieved. One cannot explain capitalism and its tendencies without also addressing these. Piketty's work involves an unreconciled inconsistency between his laws and the institutional context, which becomes problematic when one starts to think about 'inevitability'. It is problematic since the laws, rather than the empirical evidence, introduce problems in general of realism, regularity and determinism, and because this then affects forecasts for the future. Jackson and Victor focus on Piketty's prominent forecast that inequality will continue to increase. This is important, since rising inequality has consequences for ecological economics. However, they address the model procedure that underpins the forecast in terms of another model. As such, they focus on the mainstream economic aspect of Piketty's work, and in so doing they provide an ideational response to what is also a problem of ideological frameworks. That is, they contest an idea or thesis and its implication, but in so doing they reproduce the mainstream aspect of Piketty's work, which is problematic from both a Keynesian (post-Keynesian) and ecological economics perspective. Jackson and Victor's approach illustrates a tytpical dilemma for ecological economics. It inadvertently, through family resemblance, contributes to the reproduction of the problematic position of ecological concerns within dominant ways of conceiving economics. Concomintantly, Piketty's work, despite its positive aspects, reproduces a typical problem in economics. That is, the delegation of ecological concerns to a sub-discipline. In looking to the future 
Piketty opts to acknowledge but assume away ecological problems, and thus never really contests the deep problem of how economics is understood and defined.

Piketty's Capital is limited as a way to argue regarding possible futures. Capital highlights the relative significance of oil and gas to particular economies as part of the future wealth and inequality potentials of those economies (e.g. Piketty, 2014: 455-465, 537-538). At the same time, as a general point of departure, Piketty's wealth forecasts for the future assume (not without ambivalence) that the carbon problem is solved, and yet growth and economies follow old statistical patterns with reference to technological frontiers for production (Piketty, 2014: 72, 95). Though these aspects of his argument involve some tensions, in all cases Piketty is extrapolating a future based on the past. A 'this time is different argument' can often be flawed. However, equally a 'this time must be different' argument can be both a reasonable conclusion and an important positioned argument to pursue. Given that Piketty's focus is wealth and income inequality, the ecological dynamics here may seem peripheral. However, putting aside the inconsistencies in his approach, Piketty positions his work as political economy and the last sections of Capital are about desirable futures not the inevitable outcomes built into the laws. For Piketty, the focus is his global wealth tax. However, the forecasts are implicitly concerned with the future nature of viable economies in order for the forecasts to be relevant at all. Capital thus should not have put aside ecological issues, since these are fundamental. Though laudable in many ways, ideologically speaking Capital is also a lost opportunity for something more ambitious as political economy, and this lost opportunity is also methodologically grounded. Placing Capital in the context of methodology and ideology returns us to the kinds of issues raised in Ecological Economics regarding the role of economics as a knowledge framework by Nadeau (2015), Spash (2012; 2013a; 2013b) and others. Following a series of sections that progressively set out the various inconsistencies in Piketty's position and how Jackson and Victor choose to respond we argue towards the knowledge framework issue in the conclusion.

\section{Capital's three laws and the growth challenge}

The purpose of Jackson and Victor's paper is to demonstrate that a substantively different world with prosperity and no/low or degrowth remains possible despite Piketty's 3 laws (a world argued for in Jackson, 2009). ${ }^{1}$ Jackson and Victor provide an ideational response in the form of an alternative model, the key aspects of which I set out in the next section. Piketty defines capital as the total market value of everything owned by residents and governments of a given country at a given point in time, provided that it can be traded on some market [excluding human capital and wage labour]' (Piketty, 2014: 48). As he also notes, he uses 'the words capital and wealth interchangeably, as if they were perfectly synonymous' (Piketty, 2014: 47). Conceptually speaking capital becomes the net present value of all asset wealth determined in markets. This creates some degree of confusion later in Chapter 6 when he begins (following some critique)

\footnotetext{
${ }^{1}$ Jackson and Victor refer to 2 laws but for clarity we follow Piketty's original broadest account in Capital.
} 
to use a Cobb-Douglas production function, a function developed to express physical product. The concept is also quite different than the more heterodox idea of capital as the social relations of the produced means of production.

Piketty's first law just states that the total return to capital in any given period (capital's share of annual national income) derives from the rate of return and from the relative amount of accumulated capital (wealth assets) compared to annual national income. If the rate of return is higher, and/or the accumulated capital to which a return flows is greater, then more of annual national income goes to capital. The second law provides a mechanism by which the relative amount of accumulated capital grows. If saving occurs faster than economic growth (adjusted by population) then a greater proportion of annual national income becomes capital over time. This is assumed to be a long-term relation. For example, if the ratio of saving to growth is 4 for an extended period then capital will accumulate to $400 \%$ of annual national income.

It is implicit in the second law that low growth implies the potential for more rapid accumulation of capital from annual national income. This then leads in the first law to an increase in capital's share of annual national income, and especially so if the return to capital does not fall. ${ }^{2}$ For Piketty's argument it also matters who owns that capital. If capital ownership is unevenly distributed, then one can assume that consumption is negligible as a proportion for those with significantly more wealth. Thereafter, by a simple process of compounding there will be a continual increase in the concentration of capital, and thus an increase in the concentration of wealth. The greater part of Piketty's Capital is concerned with setting out data that establishes capital is mainly held privately, that its transmission is facilitated by inheritance, and that in modern capitalism one also has 'supermanagers' who control their own compensation culture (so there is a potential among the wealthy to use income and positional power to accumulate assets, and to do so whilst earning rates of return not available to others). To be clear, these are not assumptions or predicates in so far as they apply to the past. They are areas of empirical exploration. However, as areas of exploration they take as given institutional arrangements that enable them. This, as we shall see, creates problems of consistency and construction for Piketty once the empirical evidence is translated into the laws, and also when these laws are projected forwards. However, it is based on the data that Piketty claims that there are recognizable strata to which capital flows (the $10 \%, 5 \%, 1 \%$ and $0.1 \%$ ). Piketty then introduces his third and most famous law. One can observe relatively constant rates of return to capital in excess of growth over long periods. This becomes a 'fundamental force for divergence' or inequality because of asymmetric ownership (Piketty, 2014, 424).

According to Piketty, in the contemporary period the long-term rate of return has been around 4-5\%, encompassing higher rates of return for top echelons of society. Global growth has tended to be around 1-1.5\%, compared to $2.5 \%, 1950-1980$. The rate has varied across states engaged in catch-up, but all are ultimately subject to the same technological frontier. Piketty then projects this across the twenty-first century and with some comment on the following

\footnotetext{
2 It is, therefore, significant that Piketty opts for a constant rate of substitution between capital and labour of between 1.3 and 1.6 (Piketty, 2014: 221). Though he simultaneously notes that 'there is no reason why the technologies of the future should exhibit the same elasticities as those of the past' (ibid). This acknowledgement does not affect his actual procedure.
} 
century. It should be noted that he is careful to state that forecasts are problematic. He also briefly raises, though rhetorically and without substantive explanation, the question of whether we are approaching the end of growth for 'technological or ecological reasons' (Piketty, 2014: 93). However, he then sets this aside and opts to set out a long term per capita output growth rate of $1.2 \%$ for wealthy countries and based on the assumption that 'sources of energy are developed to replace hydrocarbons' (Piketty, 2014: 95). ${ }^{3}$ To be clear, Piketty simply assumes this for the purpose of making projections about growth unencumbered by concerns with possible ecological limits. He does not justify, explain or explore the assumption. Based on these dynamics and assuming no fundamental change via the introduction of institutions able to control the ownership of and returns to capital, he projects the continued concentration of wealth (Piketty, 2014: 353-360).

Clearly, continued wealth concentration creates a basic problem for no/low and degrowth approaches to ecological economics. This provides background regarding what it is Jackson and Victor feel required to respond to, though the fundamental issues have been acknowledged for decades. Daly, for example, clearly states two reasons (1974: 19). First, if more of annual national income goes to the few there is less remaining for the majority, if the system is steady state, since there can be no Kuznet 'trickle down' effects from expansion. ${ }^{4}$ Society would, therefore, be destabilised (argument here can be both functional and ethical). This destabilisation applies also to low and degrowth scenarios. Second, wealth concentration is antithetical to the transformation of societies and economies that is necessary to achieve ecological aims. For Daly, one must overcome a basic problem of identity construction around 'relative wants'. This identity formation is intrinsic to consumption-based economies whose very constitution is predicated on constantly increasing volumes and types of consumption. Such a system is based on logics of competition that legitimate inequality and that encourage symbolic consumption as the expression of inequality. A third reason is implicit in Piketty's work. Increasing wealth concentration is also the accumulation of resources by privileged groups who are then able to exert influence to sustain their interests. ${ }^{5}$ As research from the Transnational Institute makes clear, this creates institutional opposition to addressing climate change and other ecological challenges (Buxton and Hayes, 2016).

The relevant point here is that growing inequality creates a challenge or problem in so far as it can prevent the transformations required or can destabilise incipient sustainable socio-economies. Piketty's third law seems to suggest that prosperity in low or no growth scenarios will be denied to the majority and wealth concentration (growing inequality) can persist. From an ecological economics perspective this begs some kind of institutional mechanism to prevent growing inequality within a different kind of socio-economy. Daly and many others have made this point, and it is also inherent in Jackson's case in his most well-known work Propserity Without Growth where he argues for a society

\footnotetext{
3 Since the initial future periods will continue to involve catch-up growth in world per capita output is initially higher than this.

${ }^{4}$ Piketty provides an extensive constructive critique of Kuznet's work.

${ }^{5}$ Piketty merely notes that it is not illogical for oil revenue sovereign wealth funds to invest in the US since this creates political influence in pursuance of military security (Piketty, 2014, 457)
} 
based on different concepts of labour and prosperity; one more along Aristotelian lines of flourishing or well being (Jackson, 2009). However, the response in the Jackson and Victor paper introduces a potential inconsistency, based on how one accommodates to mainstream economics, which in turn reflects a problem in Piketty's approach. The combination illustrates a more fundamental dilemma for ecological economics in terms of consistency, and we develop this argument progressively in the following sections.

\section{Jackson and Victor's response to the growth problem}

Jackson and Victor begin by acknowledging that 'the prospects for prosperity without growth would appear slim at best if Piketty's thesis were unconditionally true' (Jackson and Victor, 2016: 206). They then state:

The principal aim of this paper is to test this hypothesis, i.e. to determine the extent to which declining rates of growth in national income, NI, might lead to rising capital to income ratios and thence to an increasing share of income to capital. In either formulation, much depends on the parallel movements in the rate of return on capital $r$ and on the savings rate s. (Jackson and Victor, 2016: 207)

Jackson and Victor's strategy is to construct a model that demonstrates Piketty's thesis need not be 'unconditionally true'. Their Savings, Investment and Growth in a Macroeconomic Framework or SIGMA model is based on a post-Keynesian stock-flow consistent (SFC) approach:

Following much of the SFC literature, the model is broadly Keynesian in the sense that it is demand-driven. Our approach is to establish a level of overall demand through an exogenous growth rate, $g$, and to generate the level of investment through an exogenous savings rate, s. We then explore the impacts of changes in these variables over time on the income shares from capital and labour through an endogenous rate of return, $r$, on capital. To achieve this we employ a constant elasticity of substitution (CES) production function, not to drive output as in a conventional neoclassical model, but to derive the marginal productivity $\mathrm{rk}_{\mathrm{k}}$ of capital $\mathrm{K}$ and also to establish the labour employment associated with a given level of aggregate demand. (Jackson and Victor, 2016: 208)

Clearly, the use of a neoclassical production function is no less problematic as a theory form to explore reality when employed by Jackson and Victor than it is when used by Piketty. However, Jackson and Victor attempt to justify its use based on a strategy of engagement for refutation of a prominent idea. They state that 'retaining this aspect of Piketty's analysis allows us to compare our findings more directly with his' (Jackson and Victor, 2016: 208, fn 6). As Jackson and Victor make clear, the main purpose of the exercise is to address one model approach in terms of another in order to demonstrate that no/low or degrowth need not lead to unconstrained expansions in inequality. This leads them to 'stick relatively closely to Piketty's assumptions' (Jackson and Victor, 216: 215), on the 
basis that reasonable comparison requires some family resemblance between the approaches.

Since the point at issue is to demonstrate that outcomes are more conditional than Piketty's core position seems to imply, challenging that position is pursued as a series of simulations based on a relatively simplified version of the SIGMA model. They note that a simple version of the model is sufficient for the point they want to establish. The model is closed (no international trade), the government runs a balanced budget and holds no debt (thus government spending equals tax), household wealth is held as bank deposits or equities, and the only function of banks is to act as financial intermediary matching deposits to loans. Furthermore, since the aim is to highlight that the inequality outcomes are conditional the paper is positioned as no more than a conceptual rethink of how inequality is modelled. Jackson and Victor state the model is not 'inherently data driven' (2016: 211). Data is used as part of a standard 'calibration' approach to modelling (Jackson and Victor, 2016: 207). However, the authors do state that the values chosen for the key variables in the simulations should be (and are) 'reasonable', implying that they are values that might occur (Jackson and Victor, 2016: 212). The simulations are run using different growth rates, different elasticities of substitution between labour and capital, and different savings rates.

The simulations are run for a period of 100 years and produce a series of results. First, there need be no explosive increase in inequality, even if growth falls to zero, if the rate of return also falls in order to offset the accumulation of capital assets. Second, if the elasticity of substitution between labour and capital is set to 1 then capital's share of income is stable, but rises if the elasticity is more than 1 and decreases if less than 1. However, in all cases, if income and wealth are equally distributed between workers and capitalists, inequality remains stable even as the share of income going to capital rises. Higher initial shares of income going to capital leads to greater inequality through time and this varies in the simulations from $750 \%$ higher for capital than workers over 100 years to $70 \%$ (though if retained profits are introduced for firms then the maximum is lower). Finally, higher savings rates lead to more inequality over the period.

What does this exercise achieve? The simulations allow Jackson and Victor to conclude, 'there is absolutely no inevitability at all that a declining growth rate leads to explosive (or even increasing) levels of inequality' (Jackson and Victor, 2016: 215). As we stated in the introduction this is an important point to be able to make if one is simply challenging the core claim that inequality must rise in the context of Piketty's third law. Piketty's work has been extremely prominent. The core claim within the third law that inequality will rise without limit has been widely publicized. As such, constructing a comparable model to establish that one can adjust the values of key variables in ways that demonstrate that rising inequality is not inevitable serves a useful purpose as an ideational counter. It forestalls any attempt to undercut ecological argument regarding realizing limits to growth. However, it is important to highlight a range of further points one might make regarding Piketty's approach to the next 100 years. In their absence the strategy employed by Jackson and Victor is limited in terms of pursuing an ecological economics agenda. This is by no means to 
suggest they are unaware of this, the paper merely serves one core function. It does, however, beg issues of consistency.

\section{Comparability, family resemblance and the limits of model for model argument}

Jackson and Victor's strategy is to opt to contest one model in terms of another. Comparability requires some basic similarity, creating family resemblance. The construction thus involves some degree of accommodation to what one might in other contexts have been more critical of from a methodological point of view. As already noted, the simulations adopt a neoclassical production function and apply constant elasticity. The understanding applied to this is different than is typical in a neoclassical model, but the purpose is still a form of marginal analysis. Thereafter, different values for variables are used and so the new model is run slightly differently than Piketty's core approach, which adopts a constant rate of substitution between labour and capital of between 1.3 and 1.6 (Piketty, 2014: 221) and asserts that saving rates, growth rates and rates of return on capital are stable along the lines Piketty claims will, within the three laws, result in increasing inequality. One might then argue that the new model is more sophisticated than Piketty's and that the multiple simulations consider a wider range of scenarios. However, one must still acknowledge that the new model employs a set of simplifying assumptions, is not 'data driven', and allows for calibration (a technique of data fitting).

Though the model is more sophisticated and the simulations more wide ranging this is not the same as to suggest the model is realistic. The authors make no such claim, but one might also suggest it is questionable whether it can become realistic. It faces the same basic problem all models confront. That is, the difference between use of assumption as heuristic idealism and the problem of abstraction as focus on what is genuinely representative. This is partly offset in so far as stock-flow accounting is about systems and makes no claims to account for (in so far is it explains or fully expresses) the relations it models. These are additional. Still, this is a notable problem, and one compounded by the need for accommodation to the more problematic aspects of Piketty's approach.

Furthermore, the adoption of a constant elasticity production function does something that is at least questionable for Keynesians based on the Cambridge Capital Controversy. The Controversy is a problem Piketty seems to profoundly misunderstand in Capital. Pressman summarizes the issues nicely:

Robinson questioned the marginal productivity theory of distribution when she asked how it was possible to measure this diverse thing called 'capital'. In a nutshell, the problem is that in order to determine the return to capital, we need to have the return to capital in order to add up the various things that are called capital. Yet marginal productivity theory seeks to explain the return to capital; it cannot assume what it seeks to explain [...] Piketty blames this debate on the fact that data was not available in the 1950s and 1960 s to resolve the controversy. This cannot possibly be correct. The Cambridge Controversy was a theoretical debate about the logical consistency of the marginal productivity theory of distribution. It could not, in principle be solved by any data [...] this in no way invalidates his empirical 
results. These results do not involve some vicious circle in reasoning because they are about wealth and returns to wealth (Pressman, 2016, 94).

Pressman points out that the misunderstanding does not affect Piketty's data, nor is it a core issue if one accepts that Piketty is concerned with wealth assets rather than capital as typically understood (Pressman, 2016, 93-95). However, it does matter for how he conceives of the problem, and it does matter once one starts to model in terms of growth and ownership of productive assets. The more Jackson and Victor shape their analysis around ownership of productive assets, rather than wealth in general, the more it reproduces the damaging (and essentially non-Keynesian) side of Piketty's work.

Jackson and Victor focus on the problematic aspect of Piketty's approach to capital -- the use of the function and the construction of capital and wealth. They state their model using the terminology of 'capitalists' and 'workers' and ownership of productive assets. This necessarily reproduces the shift Piketty is criticized for. That is, his concept of capital is initially broader, encompassing all assets tradable on markets, but the production function approach adopted was developed to express physical capital. Jackson and Victor reproduce the shift even if they do so with clarity. It remains the case that the shift is towards the more problematic aspect of Piketty's approach. This is a significant concession for any post-Keynesian approach.

Still, the reproduction of the problem is understandable given the point Jackson and Victor want to make. Once a model-to-model approach is adopted some degree of family resemblance is required. It is, however, still limited by its reference point and strategy of resemblance. The new model is a step towards endogenous relations, though does begin with exogenous values. Piketty assumes saving and growth to be essentially independent and also assumes savings become wealth. This is antithetical to a Keynesian position and unrealistic in so far as it puts aside complex interactive processes. It disallows a paradox of thrift and other interdependent relations, but does so to simplify the construction of the laws, which become mechanistic mathematical expression predicated on regularity. Here, one might argue that there are further strategies of critique one might have applied to Piketty's work that lead to other arguments for ecological economics in relation to the problem of no/low and degrowth, and it is here that the major issues of inconsistency begin to manifest.

\section{Different ways to argue towards ecological economics based on Piketty}

To begin with one could just as easily have focused on and refuted the three laws as adequate constructions of real relations. Piketty's derivation of an aggregated rate of return on capital (all wealth assets) conceals the different returns in different markets and sectors that are experienced. As the paradox of thrift point also highlights, the mechanics of the 3 laws lack fully expressed endogeneity and interdependence. The approach is partially neoclassical by construction of the production function, opting for independence of and a marginal approach to, key variables. It is thus antithetical to basic theoretical claims and methodological 
underpinnings in Keynesian economics. ${ }^{6}$ More importantly, stating this clearly provides a different link to the point Jackson and Victor want to make, which is that no/low and degrowth are compatible with prosperity. Specifically, that the operative verb construction for compatibility is can be. The point will become clearer as we progress.

Although Piketty's forecast for the twenty-first century highlights a continual increase in wealth and income inequality, the point of the forecast is to provide a positional argument for intervention. The data is used purposefully. Piketty is interested in establishing that inequality will increase without limit in the absence of institutional change. This provides the basis of argument for his global wealth tax. Inevitability is actually and counter-intuitively highly contingent in the way Piketty frames it. His well-known u-shaped curve for twentieth century inequality highlights, though this is not part of Piketty's argument, that real economies allow for what Karl Polanyi termed a double movement (the curtailing of a market economy in response to its negative tendencies). Piketty simply refers to the period as an exception to what he considers the more basic elements of the system (his 3 laws). However, this is to reify one aspect of the potentials of a system. In this sense, inevitability is more a product of the three laws aspect of his approach and its mechanics. The capacity for compounding based on ownership somehow becomes the primary characteristic of capitalism rather than its many and varied institutional contexts through time. This problem or inconsistency is never reconciled in Capital. There is the data or empirical findings, the three laws and then periodic acknowledgement of contingency. For example, Piketty acknowledges: 'It is hard to imagine an economy and society that can continue functioning indefinitely with such extreme divergence between social groups,' (Piketty, 2014: 297). Jackson and Victor establish that even the implausible mechanics can allow for ranges of effects on inequality. They too emphasise that the kinds of inequality that have been observed (and which the simulations allow for) invite intervention in the form of institutions: 'Even under a highly-skewed initial distribution of ownership of productive assets, it is entirely possible to envisage scenarios in which incomes converge over the long-term, with relatively modest intervention from progressive taxation policies' (Jackson and Victor, 2016: 215). ${ }^{7}$

\footnotetext{
${ }^{6}$ The problem pervades Capital. For example the reference point for a stable $\mathrm{r}$ greater than $\mathrm{g}$ is: 'In the standard economic model, based on the existence of a 'perfect' market for capital (in which each owner of capital receives a return equal to the highest marginal productivity available in the economy, and everyone can borrow as much as he or she wants at that rate), the reason why the return on capital, $r$, is systematically and necessarily higher than the growth rate $\mathrm{g}$ is the following. If $\mathrm{r}$ were less than $\mathrm{g}$, economic agents, realizing that their future income (and that of their descendents) will rise faster than the rate at which they can borrow, will feel infinitely wealthy and will therefore wish to borrow without limit in order to consume immediately (until $r$ rises above g). In this extreme form, the mechanism is not entirely plausible, but it shows that $r>g$ is true in the most standard of economic models and is even more likely to be true as capital markets become more efficient' (Piketty, 2014: 360). Piketty's point is to consider what his data is compatible with so he is arguing even if we assume neoclassical conditions $r$ will be $>\mathrm{g}$. But this does not salvage the construction.

7 Similarly, Jackson and Victor also state: "A key policy conclusion concerns the need to protect wage labour against aggressive cost-reducing strategies to favour the interests of capital. This measure would have the additional benefit of maintaining high employment, even in a low-or degrowth economy." (2016: 217).
} 
Both Piketty and Jackson and Victor are ultimately interested in arguing against possible worlds that their models forecast. Both also acknowledge that their models are contingent (though the models themselves cannot express this). Here, one might argue that in responding to problems in Piketty's construction Jackson and Victor's response is limited not just because it is a response to Piketty's concerns but because of what it focuses on within those concerns. Piketty's model focus is on what does not change (an inequality tendency) in order to argue for future change. Jackson and Victor focus on Piketty's argument for what does not change to argue that it need not be as damaging in its impacts. But it is debatable that Piketty's work genuinely supports his own 3 laws in the first place, at least in the sense of any reasonable understanding of 'inevitability'. ${ }^{8}$ For Piketty, inevitability is always held to be conditional, and so focusing on establishing the conditionality of the 'inevitability' of Piketty's claims is mainly a victory of one model over another. One should not denigrate this as an achievement, since economists take model construction seriously. It may serve a discursive strategic function. However, it may also be inconsistent in terms of what is achieved.

For example, a model may use, as Jackson and Victor suggest, 'reasonable' values. However, this tells one little about the realism of those values in the sense of how they inhere in, arise from, or affect actual institutions. This applies to both the past and the future. So, Jackson and Victor may construct a model to establish that progressive taxation can be a means to reduce inequality over time, but there remains a great deal of work to do that is not easily modeled regarding how to design systems that address the norms of equity and problems of both tax avoidance and evasion, all of which may confound a model (Morgan, 2016b). Likewise, Piketty's work has come under significant criticism regarding the viability of the institutional basis of his global wealth tax.

In broader context then, one could apply a different or further strategy to Piketty's work. That is, one might take a more methodological, philosophical or conceptual approach and argue that the role of institutions in historical processes brings into question the claim for 'inevitability' of 'laws' in an economic context. Jackson and Victor's approach seems to meet more of the expectations that economics as a mainstream discourse creates. But bear in mind, their interest is to establish that no/low and degrowth are compatible with prosperity. The point of reference is Piketty's assumptions of what does not change, but within ecological economics no/low and degrowth are deliberate-bydesign. They involve social redesign, economic restructuring, different values, and different meanings of work. As such, Jackson and Victor's point of departure seems inherently inconsistent because the problem to be addressed is also inconsistent. It is not the unrealistic regularity aspect of the work that matters for how the future is constructed. Rather, critique of the implications of this kind of work is part of making the case for future potentials.

\footnotetext{
8 To be clear, the assumption that no institutions get in the way is also part of an argument that some kind of institution will be needed -- and the socio-political instabilities consequent to compounding may call these forth. Piketty's approach to such problems exhibits some ambivalence. In the end Piketty opts for a kind of empiricism that emphasizes determinism in the absence of entirely foreseeable changes. This is understandable since his target audience was mainstream economists (this also explains his use of the production function and the way he justified his claims about rates of return etc.).
} 
In ecological economics, a future of no/low and degrowth are not assumed to be inadvertent aspects of capitalism (such as the current concerns with secular stagnation). There is significant debate regarding the nature of future systems -- whether Green Keynesianism is viable, whether capitalism can be environmentally sustainable and so forth. However, given the basic point that no/low and degrowth are deliberate-by-design one could reasonably critique Piketty's approach based on its problems of realism regarding the construction of the laws and then the conceptual problems and inconsistencies regarding institutions, and move on to what no/low and degrowth can be compatible with in further and broader ways. Furthermore, one could do so by establishing that Piketty's work is not only antithetical to Keynesian approaches to theory (in a methodological sense) but also to ecological economics. This would then allow one to focus on the assumptions Piketty applies to his forecasts for the twentyfirst century in a different way.

\section{Piketty's Capital as inadvertently antithetical to ecological economics}

Ecological economics is not a unified field of inquiry (Özkaynak, et al., 2012). Different proponents take quite different views on where its significant emphases should lie and what its strategies should be -- not least the degree to which it ought to make concessions to, in order to engage with, neoclassical influenced environmental economics (see Spash, 2009). Jackson and Victor's approach expresses some of the dilemma here because it takes as its point of reference Piketty's approach to a production function. Piketty is not an environmental economist but Jackson and Victor address his work in terms of its implications for environmental concerns, and do so by constructing a model with sufficient family resemblance to allow them to make the point that the third law is not an insurmountable barrier to low/no or degrowth. However, one might also argue that the concession requires inconsistency in terms of both postKeynesian economics and ecological economics.

Though not unified, ecological economics does involve some basic commitments (Gowdy and Erickson, 2005). An economy involves material processes, and so energy use is basic to all forms of actual economic activity. Material processes involve the transformation of aspects of the environment into resources, which in turn involves basic thermodynamic relations and ecosystem consequences. An economy is embedded within a society and both are embedded within a local and global environment. Ultimately the global environment and its ecosystems create real limits to economic activity. At the same time, the environment, society and economy co-evolve, and so have history as complex systems in process. Different ways of constructing an economy and different social forms can become 'locked in', and complexity means that systems involve thresholds, breakpoints, and positive feedback loops. Understanding and explaining relations necessarily involves degrees of ignorance, and also basic uncertainty regarding at what point problematic economic activity based on forms of legitimating social design become deeply harmful, and perhaps irreversible in their environmental consequences. The combination of material process and real limits, complexity, co-evolution, lock-in and uncertainty means that some ways of conceptualising and theorizing within economics are misleading, if not substantively incorrect (see Nadeau, 2003, 2008). 
Unlimited and smooth substitution between forms of 'natural' and produced capital, based on marginal analysis, model economic systems as though they were based on stable relations, and as though they were predictable -- implying the ability to precisely manage the environment as simply discrete resources. Moreover, the reliance on approaches such as abatement modeling in conjunction with cost-benefit analyses tends to assume rational behaviour (within constraints, but defined as calculative and instrumental). This relies on methodological individualism and tends to ignore, stylise or under-emphasise social and economic lock-in, whilst assuming that market processes can be relied upon to ultimately deliver environmental sustainability. From this perspective there can be constructive attempts to 'nudge' behaviour, but this is as corporations or consumers prior to as citizens. Moreover, in recognizing the need for global agreements regarding limiting some kinds of activity, economics tends to encourage market conforming perspectives. This reduces the scope for, and urgency of, intervention based on deliberative collective conduct in order to transform societies in accordance with ecological concerns (and based on a precautionary principle). It also inverts the relation of dependency between economies and the environment - prioritising the economy over the environment. It leads to question forms that seem rational, but are in broader context bizarre rather than reasonable. For example, at what point does it become cost effective to start investing in ways to stop destroying the environment in which we live?

This is familiar material to ecological economists, but it is worth stating here because it bears on how we view Piketty's work. Piketty's approach to theory is not only antithetical to Keynesian approaches it is also antithetical to the methodological basis of theoretical tenets that are basic to ecological economics. Piketty's approach to wealth and income inequality is based on marginal analysis and fixed relations. It cannot deal adequately with endogeneity and interdependence, and thus complexity. It cannot deal with co-evolution, despite that the 3 laws seem to be a form of evolution. The laws actually express mechanistic effects of stringently defined regular relations rooted in independent variables -- creating a contradiction or tension in terms of 'inevitabilities' in a situation of institutions and societies, which must surely have thresholds and breakpoints for what will be tolerated. This is explicit in Piketty's claim that the third law is historically conditional and tacit in his positional argument for future institutional change (a wealth tax). This, of course, may not seem that relevant to ecological economics because Piketty's focus is wealth and income inequality and most of the material in Capital concerns the past. However, it is important in so far as the work is prominent and begs reply, since the form of the reply can reproduce some of the broader problems to which it is addressed. That is, the discursive power of the field of economic knowledge. Jackson and Victor's work involves this problem. For example, not only does the use of the production function require the use of marginal analysis it also introduces the problem of substitution of factors of production that affects how natural resources are conceptualised. ${ }^{9}$ Natural resources are not substitutes with

\footnotetext{
${ }^{9}$ As one referee noted: the use of the term margin is not always mainstream, it can be a matter of adaptive metaphor used in ways that are focused on process and complexity and contingent activity (including convention). For example, Keynes' original argument for marginal efficiency of capital.
} 
capital and labour but rather complements subject to limits. Any attempt to incorporate them into a standard production function is tortuous and occurs in order to preserve the mathematical expression of theory rather than to adequately express an ecological reality. Substitution mis-poses the problem and violates the first law of thermodynamics, as Georgescu-Roegen made clear many years ago (1971).

Piketty's approach is also important once one begins to consider the future. His forecasts across the next 100 years are indicative of a variety of problems encountered by ecological economists. Capital highlights the relative significance of oil and gas to particular economies as part of the wealth and inequality potentials of those economies in a global context, including the rise of China (Piketty, 2014: 455-465, 537-538). The major focus here is rents and the material for the continued accumulation of wealth based on capital derived from ownership of oil and gas assets (and assets bought with such assets). Piketty acknowledges that what will happen over the next century is determined by the price of oil in the context of the discovery of new deposits and new sources of energy and 'how quickly people learn to live without petroleum' (Piketty, 2014: 459). Piketty also opts for a long-term growth rate for wealthy countries of $1.2 \%$ based on a judgment regarding prior technological frontiers for production (and this provides a boundary as other economies growth varies based on catch-up). This aspect of the argument rests on the assumption that 'sources of energy are developed to replace hydrocarbons' (Piketty, 2014: 95). As already noted, no attempt is made to justify the assumption. Moreover, there is clearly a tension here and this is more important than the specifics of the quantities by which inequality is held to ineluctably rise. The calculation for global wealth over the century rests partly on extrapolation of oil and gas assets whilst the long-term growth rate is subject to a technology condition that acknowledges hydrocarbons must be replaced. One can, of course, read this sympathetically as a transition tension recognizing real world constraints but not actually investigating them in any substantive way.

However, there is something more to the problem if we begin to think in terms of the characteristics of ecological economics: uncertainty, deliberative potential and the future nature of viable economies in order for forecasts to be relevant at all. Piketty's approach to the problem of hydrocarbons is a subset of the inconsistent argumentation structure he applies to the inevitability of inequality. The forecast relies on what does not change within tendencies, but in this case there is acknowledgement that something basic must be changing in order for the tendency to be possible at all. People must 'learn to live without petroleum' and we will have to 'replace hydrocarbons'. Consider what this actually means. Replacing hydrocarbons is not simply a narrow issue of fuel or energy. It is not simply an issue of hydrocarbons' absence from economies but fundamental difference in future economies. Capitalism is a disputed term. Based on various definitions it can extend from several thousand years to just a few hundred. However, it is the growth spike period of industrialised and then consumer oriented capitalism that is relevant for Piketty's argument and forecasts. Modern capitalism has been carbon capitalism. Hydrocarbons and other carbon resources have been basic to almost all material processes and a huge swathe of material things (from industrial agriculture's dependence on pesticides and the ammonia used for nitrogen in fertilizer, to road surfaces, 
plastics, pharmaceuticals, dyes and synthetic rubber). ${ }^{10}$ If one takes a countryby-country approach across the industrialised period it can seem as though there are many cases of industrialisation over an extended period, and so one can reasonably extrapolate a future rate of growth and technological frontier from this past of many cases. However, the whole is really only one case within which there have been a series of identifiable waves based on technological restructurings. ${ }^{11}$

The more one considers how different a future economy could be if it is not a hydrocarbon economy then the less reliable this single case becomes as a way to extrapolate regarding future growth and technologically referenced limits. Piketty's own assumption makes any use of the past deeply problematic as a guide to the future. This is a point Jackson and Victor could have made and so by-passed the model procedure they engage in. This would avoid the inconsistency inherent in the family resemblance problem. It would, however, create a different issue in so far as the lack of a model might cause some mainstream economists to dismiss the argument as 'uneconomic' (a dilemma Piketty also faced in adopting the production function and some of his argument). So, there remains a basic tension in terms of conforming an argument to meet expectations. One might also note that an unintended consequence of Jackson and Victor's approach is to close down a more sympathetic reconstruction of Piketty's concerns. A model-for-model approach formally focuses on one side of Piketty's inconsistency, whilst in an ecological context inheriting that inconsistency, since institutional claims must still be made or assumed. Jackson and Victor presuppose the centrality of the production function construct in Piketty's work (and its constant elasticity of substitution). However, one could also consider Piketty's raw data as empirical work and divorce it from the mainstream devices used to present the data and intended to persuade a mainstream audience. This would then open up the possibility of a more realistic approach to institutions, that 'thicken' Piketty's work as theory. ${ }^{12}$

The point remains that replacement is not a simple substitution of one primary resource base for another where previous quantified relations will continue to hold. There are profound issues regarding a transformed socioeconomy based on quite different resources, social design, technologies and norms. I don't make this point in order to encourage recklessness or irresponsibility (the lack of a deterministic relation for the future implies growth can be unconstrained and prosperity will take care of itself), but rather the reverse, based on the need for circumspection. The hydrocarbon issue involves intrinsic uncertainty. The systemic issues surrounding hydrocarbons are fundamental. This requires us to think carefully about those issues and this is a

\footnotetext{
10 Political economists recognized this in the early industrial revolution, but the recognition then did not become basic to how economics defined itself (a material process - a point made by Bernard Breaudreau, among others). Stanley Jevons states (and one can replace coal with hydrocarbons): 'Coal in truth stands not beside but entirely above all other commodities. It is the material energy of the country -- the universal aid -- the factor in everything we do. With coal almost any feat is possible or easy; without it we are thrown back into the laborious poverty of early times' (Jevons, 1865: viii).

11 The most familiar conceptualisation of this is associated with Kondratieff.

12 As Martins (2015) argues one can then differentiate Piketty's approach as 'political arithmetic' and mainstream presentational device and focus on the political arithmetic.
} 
matter of deliberative argument and substantive policy. These are core to ecological economics.

Piketty's approach collapses into a tension between past trends and future quantities without giving proper consideration to viable economies and how one might make the case for them. This is inadvertent since he is a leftleaning social democrat and so sympathetic to environmental concerns. ${ }^{13}$ However, it is nonetheless important since the problem is intrinsic to how he structures both theory and forecasts. Moreover, it is important because the overall approach reproduces a typical problem in economics. That is, the delegation of ecological concerns to a sub-discipline. Piketty opts to assume those concerns away, and thus never really contests the deep problem of how economics is understood and defined. ${ }^{14}$ This becomes clear when one considers the problem of both the production function approach and then the institutional basis of future viable economies, which rests on institutional issues of design. These are both matters that Jackson and Victor reproduce in order to address the problem of inequality to advance an ecological agenda. Again, this raises the issue of what is achieved when one addresses an argument in its own terms, and this remains a dilemma for ecological economics. As for Piketty, one cannot reasonably assume ecological concerns away and pursue Piketty's focus on future inequality. And, one should not want to do this as a self-proclaimed political economist.

A 'this time is different argument' is often problematic, but equally a 'this time must be different' argument can be justified in both senses of that word (what seems necessary and what can be supported via evidential claim). Piketty recognizes there is an issue of 'how quickly people learn to live without petroleum' (Piketty, 2014: 459). However, the more appropriate discursive context based on the evidence is how quickly they respond to the failure to learn. This leads to the currently more relevant context of the need to survive the consequences of that current failure in order to make the future. From this point of view, Piketty's assumptions and forecasts are a lost opportunity for a more effective positional argument regarding the future. This could have been more not less evidence based. Complexity and uncertainty do not prevent this, rather they point to the need for ideological contestation of the frameworks that continue to enable pathological systems of lock-in. That is, a critique of the realism of theory, models and ideational commitments within economics that either put aside ecological concerns or reduce to environmental economics. The consequences are clear when one considers the contradictory potentials within the Paris Agreement, COP 21 (Morgan, 2016) and the recent UNEP Emissions Gap Report (2016). The election of Donald Trump as President of the U.S.A only adds additional uncertainty (see Fullbrook and Morgan, 2017).

\footnotetext{
${ }^{13}$ For example, Piketty (2014: 567-569) notes the Stern Nordhaus debate over discount rates but says no more than that 'public debate' is crucial in the future and that we should favour mitigation over adaption. This does not contest the environmental economics foundation of both arguments and the acknowledgement has no bearing on the forecasts he has already made, subject to assumptions that put the problem aside.

${ }^{14}$ Clearly, assumptions are integral to any argument. Some things must be assumed in order for that argument to be constructed. It is not the use of assumptions that is at issue but rather how reasonable those assumptions are. This is basic to constructive methodological critique.
} 


\section{Conclusion: political economy, methodology and ideology}

In recent months the spotlight in terms of issues of inequality has begun to shift from Piketty to the work of Milanovic (2016). ${ }^{15}$ However, from an ecological economics perspective the core issues regarding the future remain the same. One cannot consider the future whilst assuming ecological issues away. They are intrinsic to the possibilities of almost all other scenario foci, including inequality. This, of course, is central to Jackson's main work, which is one reason why the Jackson and Victor paper provides an interesting and relevant way to make the points we have addressed. In terms of Piketty, a more appropriate point of departure would have been to ask: what kind of economy would it be prudent to opt for in order to have any kind of prosperity at all? By contrast, Piketty essentially asked: what kind of wealth concentration follows from unconstrained capitalism within which the carbon problem has been solved? Based on the arguments made here, this latter question is impossible to address adequately because of the reality that lies behind the former unasked question. Yet at the same time Piketty's question frame is one the world has taken seriously and Jackson and Victor thus find it necessary to provide a response to it. The response is important precisely because of the discursive prominence of Piketty's question frame. However, if we place the need to respond in an ecological economics context it becomes clear that Jackson and Victor provide an ideational response to a situation created by ideological frameworks. That is, they contest an idea or thesis and its implication, but in so doing they inadvertently, through family resemblance, contribute to the reproduction of the problematic position of ecological concerns within dominant ways of conceiving economics. This begs broader issues of the reform of economics (see Morgan, 2015c).

Consider what Piketty achieves. It was widely acknowledged that mainstream economics over the last few decades has paid little attention to inequality (despite the important work of post-Keynesians, such as James Galbraith, and others such as Robert Wade). More critically, the very theory structure of much of economics served an ideological function in terms of marginalizing inequality -- marginal productivity of labour assumes factors receive their appropriate and hence just rewards, GDP measures conflate growth and economic benefits without considering either distribution or qualitative aspects of prosperity, growth theory in general is highly stylized and the Kuznet thesis has provided a justification for dynamics where a better world is always just around the corner for the many in a system where the few reap disproportionate rewards now. ${ }^{16}$ Piketty's major achievement was to bring the problem of inequality back into the mainstream but based mainly on overwhelming data. $\mathrm{He}$ is notably critical of economists' reliance on

\footnotetext{
${ }^{15}$ Milanovic explores and seeks to explain how inequality between countries is reducing even as inequality within countries has risen. As with Piketty's work this has involved some reductive popular comment and focus -- notably the 'elephant curve' produced in conjunction with Christoph Lakner (initially a graph displaying data 1998-2008 for growth in average per capita household income by percentile group (it looks like an elephant with trunk raised).

16 For example, Martins (2016) argues that neoclassical economics cannot adequately incorporate distributional justice from an ecological and normative point of view (with reference to strong sustainability and a circular economy).
} 
mathematical models without use of evidence or empirics. However, as much of the subsequent constructive critique of his work within political economy has pointed out this does not mean his own theory is adequate (again see Fullbrook and Morgan, 2014). As we have illustrated, it remains rooted in problematic methodological positions. One reason for this is that the intended audience of Capital was the economics profession, and so the reference points for theory were always likely to be those comprehensible to the mainstream of that audience. However, this leads Piketty to reproduce problematic aspects of that theory, and thus to his work serving to reinforce the broader ideological-asknowledge framework he partially addresses. This is a dilemma familiar to ecological economists as they seek to deal with environmental economists and garner policy influence. For example, the controversy over The Economics of Ecosystems and Bio-diversity project (TEEB).

From an ecological perspective, Piketty's approach to the future is likewise problematic. It can be read as problematic from the point of view of ideological-as-knowledge framework issues. Piketty's work thus leads back to a range of issues familiar to ecological economists. Nadeau (2015) has argued that mainstream economics continues to be influenced by its history of ideas and that a core problem remains the reliance on formalism, which conflates models with science whilst sacrificing realism. This has become the template for environmental economics. Though Piketty's work is not formalistic in the sense of absence of historical data, it is problematic in terms of the realism of its theoretical constructs, in terms of methodological underpinnings, and future extrapolations. It thus leads to problems in terms of ontology (the implicit assumptions about the nature of reality that inform the position). As Nadeau notes, the most influential ecological economist to consider ontology is Spash (notably influenced by Lawson's work, e.g 2015; see also Morgan, 2015b, 2015d, Morgan and Patomäki, 2017). Spash (2012) makes the case that it is based on what is ontologically different from environmental economics that ecological economics can be distinguished. Its difference involves commonalities between varieties of ecological economics in terms of the adequacy of each approach to a real world that is not reducible only to what we believe (see previous section, Özkaynak, et al., 2012; Gowdy and Erickson, 2005). This in turn provides grounds for constructive and purposive dialogue and critique in terms of theory and policy. It enables ideological contestation of frameworks that continue to enable pathological systems of lock-in. It provides grounds for critique of how knowledge is judged (for example, Spash's critique of citation analysis, 2013a). Furthermore, it provides a resource in argument regarding ecological economics commitment to diversity as pluralism, since pluralism must have limits based on what is adequate to reality (Spash, 2013b; Spash and Ryan 2012). This, of course, does not resolve issues of strategic difference for policy argument and influence. This remains a dilemma, where argument must still be made for more-or-less radical versions of ecological economics, and this is a point consistently made by Söderbaum (e.g. 2015).

Unfortunately, Piketty's approach to the next 100 years undercuts exploration of any of the above. However, it would be unreasonable to vilify Piketty for this lack. His work is a product of a discourse within a system that produces and reproduces knowledge in ways that constrain and enable (e.g. Katarzyna et al, 2017). Within those constraints it is in many ways a radical piece 
of work. This does not prevent constructive critique of what has been achieved, how this is responded to and what has been inadvertently contributed to. A simple assuming away of ecological concerns encourages complacency. It does not foreground the important challenges confronted, and it does not provide a way to acknowledge the genuine scale of the problem. Nor does it provide an appropriate conception of inevitability in order to begin to shift norms and values. From an ecological economics point of view it is deficient as a way to conceive political economy, since it lacks a critical institutional approach to ecological issues (see Vatn, 2005, 2015). This also becomes clearer when one considers Jackson's main work, which articulates the ultimate problem to be addressed: 17

Society is faced with a profound dilemma. To resist growth is to risk economic and social collapse. To pursue it relentlessly is to endanger the ecosystems on which we depend. For the most part, this dilemma goes unrecognized in mainstream policy [...] The sheer scale of the task is rarely acknowledged [...] Never mind that all our institutions and incentive structures continually point in the wrong direction. The dilemma, once recognized, looms so dangerously over our future that we are desperate to believe in miracles. Technology will save us. Capitalism is good at technology. So let's just keep the show on the road and hope for the best. This delusional strategy has reached its limits [...] None of this is inevitable. We can't change ecological limits. We can't alter human nature. But we can and do create and recreate the social world. Its norms are our norms. Its structures and institutions shape and are shaped by those norms and visions. This is where transformation is needed. (2009: 187188)

\section{References}

Buxton, N., Hayes, B., 2016. The Secure and the Dispossessed: How the military and corporations are shaping a climate-changed world. Pluto Press, London

Daly, H., 1974. The economics of the steady-state. American Economic Review 64 (2), 15-20

Fontana, G., Sawyer, M., 2016. Towards post-Keynesian ecological macroeconomics. Ecological Economics. 121, 186-195

Fullbrook, E., Morgan, J., editors. 2014. Piketty's Capital in the Twenty-First Century. WEA/College Books, London

Fullbrook, E., Morgan, J., editors. 2017. Trumponomics: Causes and consequences. WEA/College Books, London, forthcoming April

Georgescu-Roegen, N., 1971. The Entropy Law and the Economic Process. Harvard University Press, Cambridge, Ma

Gowdy, J., Erickson, J., 2005. The approach of ecological economics. Cambridge Journal of Economics 29 (2), 207-222

\footnotetext{
${ }^{17}$ It is perhaps also worth noting here that the problem of development remains unreconciled in Jackson's Prosperity Without Growth since he advocates growth for development and so seems to equate the two. This remains a problem for post-Keynesians and for Green Keynesianism in terms of demonstrable consequences of differently posed economic activity.
} 
Holt, R., Pressman, S., Spash, C., 2009. Post-Keynesian and Ecological Economics: Confronting Environmental Issues. Edward Elgar, Cheltenham, UK

Jackson, T. 2009. Prosperity Without Growth: Economics for a finite planet. Earthscan, London

Jackson, T., Victor, P., 2016. Does slow growth lead to rising inequality? Some theoretical reflections and numerical simulations. Ecological Economics 121, 206-219

Jevons, W. S. 1865. The Coal Question. MacMillan, London

Katarzyna, G., Scharbert, A., Soder, M. 2017. Leaving the mainstream behind? Uncovering subjective understandings of economic instructors' roles. Ecological Economics 131, 485-498

Lawson. T., 2015. The Nature and State of Modern Economics. Routledge, London

Martins, N., 2015. Inequality, sustainability and Piketty's Capital. Ecological Economics 118, 287-291

Martins, N., 2016. Ecosystems, strong sustainability and the classical circular economy. Ecological Economics 129, 32-39

Milanovic, B. 2016. Global Inequality: A new approach for the age of globalization. Harvard University Press, Cambridge, Mass.

Morgan, J., 2015a. Piketty's Calibration Economics: Inequality and the dissolution of solutions? Globalizations 12 (5), 803-823

Morgan, J. 2015b. Seeing the potential of realism in economics. Philosophy of the Social Sciences 45 (2), 176-201

Morgan, J. 2015c. Is economics responding to critique? What do the UK 2015 QAA subject benchmarks indicate? Review of Political Economy 27 (4), 211-232

Morgan, J. editor. 2015d. What is Neoclassical Economics? Debating the origins, meaning and significance. Routledge, London

Morgan, J., 2016a. Paris COP 21: Power that speaks the truth? Globalizations 13 (6): 943-951

Morgan, J., 2016b. Corporation tax as a problem of MNC organizational circuits: The case for unitary taxation. British Journal of Politics and International Relations 18 (2), 463-481

Morgan, J., Patomäki, H. 2017. Contrast explanation in economics: its context, meaning and potential. Cambridge Journal of Economics forthcoming

Nadeau, R., 2003. The Wealth of Nature: How mainstream economics has failed the environment. Columbia University Press, New York

Nadeau, R., 2008. The economist has no clothes. Scientific American April 1st

Nadeau, R., 2015. The unfinished journey of ecological economics. Ecological Economics 109, 101-108

Özkaynak, B., Adaman, F., Devine, P. 2012. The identity of ecological economics: retrospects and prospects. Cambridge Journal of Economics 36 (5), 11231142

Piketty, T., 2014. Capital in the Twenty-First Century. Belknap Press, London

Pelenc, J., Ballet, J., 2015. Strong sustainability, critical natural capital and the capability approach. Ecological Economics 112, 36-44

Pressman, S., 2016. Understanding Piketty's Capital in the Twenty-First Century. Routledge, London 
Söderbaum, P., 2015. Varieties of ecological economics: Do we need a more open and radical version of ecological economics? Ecological Economics 119, $42-423$

Spash, C. editor. 2009. Ecological Economics: Critical Concepts in the Environment, four volumes Routledge, London

Spash, C., 2012. New Foundations for ecological economics. Ecological Economics $77,36-47$

Spash, C. 2013a. Influencing the perception of what and who is important in ecological economics. Ecological Economics 89, 204-209

Spash, C., 2013b. The shallow or the deep ecological economics movement? Ecological Economics 93, 351-362

Spash, C., Ryan, A., 2012. Economic schools of thought on the environment: investigating unity and division. Cambridge Journal of Economics 60 (2), 1091-1121

UNEP. 2016. Emissions Gap Report. UNEP, New York

Vatn, A., 2005. Institutions and the Environment. Edward Elgar, Cheltenham

Vatn, A., 2015. Environmental Governance: Institutions, Policies and Actions. Edward Elgar, Cheltenham 